\title{
Overtourism as a perceived threat to cultural heritage in Europe
}

\author{
Bailey Ashton Adie
}

Solent University, Southampton, UK

Martin Falk

Shanghai Lixin University of Accounting and Finance, Shanghai, China

Austrian Institute of Economic Research (WIFO), Vienna, Austria

Marco Savioli

University of Salento, Lecce, Italy

Rimini Centre for Economic Analysis (RCEA), Waterloo, Canada

\begin{abstract}
According to a 2017 survey, approximately two in five European residents believe that the number of tourists poses a threat to the continent's cultural heritage. In order to investigate the determinants of this perception, the data from this survey of 26,000 residents was used to estimate ordered probit models. The results from these reveal that the probability of overtourism being viewed as a threat to cultural heritage is significantly lower for residents living near historical monuments, sites or festivals. The perception of overtourism as a threat is generally higher in cities in comparison with rural areas.
\end{abstract}

Keywords: overtourism, cultural heritage, Europe, ordered probit model

\section{Data Availability}

The data that support the findings of this study are openly available in GESIS Data Catalogue at http://dx.doi.org/10.4232/1.12959. Reference number: Eurobarometer 88.1 (ZA6925, September-October 2017) Cultural Heritage, Future of Europe, Attitudes of European citizens towards the environment. 


\section{INTRODUCTION}

Tourism to cultural sites and urban destinations is becoming increasingly popular. However, as cultural heritage sites tend to attract large numbers of tourists, overcrowding at these is a growing issue (Neuts \& Nijkamp, 2012). Negative impacts of overtourism include traffic and parking problems in historic centres, resident irritation as a result of misbehaving tourists, rising cost of living for local residents, visitor dissatisfaction, and substantial wear and tear to the heritage (Adie, 2019; Cheung \& Li, 2019; Neuts \& Nijkamp, 2012; Phi, 2019; Rasoolimanesh, Taheri, et al., 2019). The impact on local residents' perceptions of heritage sites and tourism is visible in Rasoolimanesh, Taheri, et al. (2019) wherein residents in close proximity to historic sites are more negative not only towards tourism development but also heritage preservation when compared with those who lived further away. Given the impact that location may play in residents' feelings towards heritage and tourism, this note investigates the perception of overtourism as a threat to cultural heritage sites within Europe.

While the growing unrest towards overtourism in general has been documented globally (Novy \& Colomb, 2019), there is substantial tourist overcrowding throughout Europe (Seraphin, Sheeran, \& Pilato, 2018). For example, Tripadvisor reported that, in 2018, the main tourist attractions in Europe suffered from long queues with a waiting time between 1 and 2.5 hours. ${ }^{1}$ This indicates potential overcrowding at European cultural heritage sites,

\footnotetext{
${ }^{1}$ The tourist attractions include London Eye, Sistine Chapel and Vatican Museum, Colosseum, Catacombs Paris, Eiffel Tour, St Peter's, Tower of London, Van Gogh Museum Amsterdam, Notre Dame Cathedral. "TripAdvisor reveals world's 10 worst tourist attractions for queues" https:/www.news.com.au/travel/world-travel/europe/tripadvisor-reveals-worlds-10-worst-touristattractions-for-queues/news-story/8c08159e8366cb2fcfa83aeaedbafce3 (accessed 4 January 2019).
} 
which may lead to negative perceptions among European residents towards tourist activities. While a couple of scholars have highlighted the threat that overtourism represents for heritage sites (Adie, 2019; Seraphin et al., 2019), few studies have been undertaken which analyse the perceived threat to cultural heritage from overtourism through the use of representative micro level data. Recent exceptions include case studies for cultural heritage sites or cities in Spain (Muler Gonzalez, Coromina \& Galí, 2018), Belgium (Neuts \& Nijkamp, 2012) and Italy (Popp, 2012). However, these studies are difficult to generalise as they are based on small surveys and limited in scope. Thus, this note is the first study on the determinants of the perception of overtourism as a threat to cultural heritage using a representative and comprehensive dataset for 27 EU-countries.

\section{CONCEPTUAL BACKGROUND AND EMPIRICAL MODEL}

The empirical model is motived by theoretical and empirical studies that show that the perceptions of local inhabitants on tourism effects are by no means homogeneous and are influenced by many variables. The first hypothesis is that the probability of perceiving overtourism as a threat to cultural heritage sites is higher for residents living near cultural heritage sites. Given their close geographic proximity, these residents would be first-hand witnesses to the site's degradation from overtourism as well as feel the effects themselves, resulting in more negative perceptions of tourism (Litvin, Smith, \& McEwen, 2019). Additionally, residents close to sites may feel high levels of site ownership, which is tied to their sense of place, driving a community conservation focus and resulting in a backlash against tourism activities (Cheer, Milano, \& Novelli, 2019; Vong, 2015). Furthermore, while local residents may also benefit from tourists, particularly if they are active stakeholders in 
the local tourism industry, urban environments are economically diversified and therefore the entirety of the local community would not be dependent on tourist income, which results in more negative perceptions of tourism activities (Amore, 2019; Ashworth \& Page, 2011; Rasoolimanesh, Roldán, et al., 2017).

H1: Overtourism perception as a threat of cultural heritage sites is higher for residents living near cultural heritage sites.

The second hypothesis comes from the fact that overtourism backlash in the form of protests and civil unrest has been almost exclusively found in urban centres (Novy \& Colomb, 2019), which may be tied to the continuing growth in urban tourism (Amore, 2019).

$\mathrm{H} 2$ : The perceived threat of overtourism is greater in cities.

The data for this analysis originates from the Eurobarometer 88.1 survey of September 2017, which provides information for citizens aged 15 and over in the 28 member states of the European Union and two other European countries. ${ }^{2}$ About 6 per cent of respondents did not provide information on the perceived threat of overtourism. A probit analysis shows that members of a higher social class, people living in large cities and those living near a cultural site show lower non-response rates (results are available upon requests).

The dependent variable of our model measures the perception that "the number of tourists visiting certain areas poses a threat to Europe's cultural heritage". The perception is measured on an ordinal variable consisting of four categories: (1) totally disagree, (2) tend to disagree,

\footnotetext{
${ }^{2}$ https://www.gesis.org/eurobarometer-data-service/survey-series/standard-special-eb/study-overview/ (accessed 2 February 2019).
} 
(3) tend to agree and (4) totally agree. In order to account for the ordinal nature of this variable and for the fact that the distances between the different categories are not equivalent, the ordered probit model should be employed. In the ordered probit model we employ, the latent variable, $Y_{i}^{*}$, is defined as following:

$$
\begin{aligned}
Y_{i}^{*}=\sum_{k=1}^{K} \beta_{k} X_{k i} & +\sum_{c=1}^{28} \beta_{c} \text { Country }_{c i}+\sum_{l=1}^{2} \beta_{l} \text { Location }_{l i}+\sum_{p=1}^{3} \beta_{p} \text { Proxmity_culture }_{p i} \\
& +u_{i}
\end{aligned}
$$

where $i$ is the respondent. $Y_{i}^{*}$ is the latent response variable representing the overtourism perception. Location consists of two dummy variables for residents in large cities and small cities, respectively, with rural areas as the reference category. Proxmity_culture denotes a set of dummy variable for residents with a proximity to cultural attractions (historical monuments and sites, works of art, for example in museums or galleries, and festivals) that are related to Europe's culture and history; $X_{k i}$ are the $K$ covariates representing the socioeconomic characteristics and $u_{i}$ is the error term. The observable dependent variable, $Y_{i}$, is an ordinal variable ranging between 0 and 3 ,

$$
Y_{i}=\left\{\begin{array}{l}
0 \text { if }-\infty<Y_{i}^{*} \leq \gamma_{1} \text { (totally disagree) } \\
1 \text { if } \gamma_{1}<Y_{i}^{*} \leq \gamma_{2} \text { (tend to disagree) } \\
2 \text { if } \gamma_{2}<Y_{i}^{*} \leq \gamma_{3} \text { (tend to agree) } \\
3 \text { if } \gamma_{3}<Y_{i}^{*}<+\infty \text { (totally agree) }
\end{array}\right\}
$$

where $\gamma_{1}, \gamma_{2}, \gamma_{3}$ are the cut-off points of the distribution of the latent measure of overtourism perception, which are to be estimated along with $\beta$, the vector of coefficients. The ordered response model is estimated using maximum likelihood techniques. 


\section{EMPIRICAL RESULTS}

Table 1 shows the coefficients and the marginal effects of the ordered probit estimates for the determinants of perceived overtourism threat. Marginal effects are calculated for the category "totally agree" (marginal effects for the remaining categories are available upon request). H1 can be rejected. The estimates show that respondents living near historical monuments or sites or those living near festivals have a lower probability of perceived threat from overtourism (-0.6 and -1.7 percentage points respectively totally agree). Additionally, residents of large cities have a higher propensity to totally agree that cultural monuments are threatened by overtourism ( +1.3 percentage points). Residents of large cities are the most concerned with the threat presented by overtourism (positive and significant coefficient), followed by small cities (positive coefficient) and then rural areas. Therefore, $\mathrm{H} 2$ cannot be rejected.

\section{$<<$ INSERT TABLE 1 HERE $>>$}

Commenting briefly on the control variables, social class is of great importance as members of the middle and upper-middle classes have a higher probability of strongly agreeing that Europe's cultural heritage is threatened by overtourism (with marginal effects for totally agree of 1.2 percentage points). This perception does not vary significantly across age and gender. However, the perceived threat from overtourism does vary considerably from country to country. The marginal effects are greatest for the inhabitants of Slovakia (SK), Poland (PL), Finland (FI), Croatia (HR), and Ireland (IE) (with marginal effects for totally agree ranging between 12 and 15 percentage points). This is of particular interest as these countries, with the noted exception of Croatia, have not experienced many anti-tourism 
protests. ${ }^{3}$ In countries where the unrest around overtourism is most pronounced (i.e. Spain and Italy, ES and IT, according to \#overtourism on twitter) are in the middle range, while the perception of overtourism as a threat is lowest in the Scandinavian countries, Germany, Denmark (SE, DE-EAST, DK) as well as in Cyprus and Greece (CY and GR).

To test robustness, a composite variable "living near cultural attractions" was created, pulling together the three separate variables into one (living near historical monuments or sites, works of art or festivals). This was done to account for possible multicollinearity between the separate variables. Unreported results show that this composite indicator is not significant (with a z-stat of -0.18). Finally, a narrower definition of proximity to cultural attractions was used (based on the question "Do you live in a historic environment, area, city, or building that is considered as being of cultural heritage value"). Approximately 19 per cent of the respondents state that they live near such sites. However, this renders another non-significant estimate (with a z-stat of -0.17), suggesting that the results of the main specification are robust.

\section{CONCLUSIONS}

While 37 per cent of European residents consider that tourism poses a threat to cultural heritage sites, the ordered probit estimates show that this perception strongly depends on the degree of urbanity in which they reside and their proximity to cultural sites. People living in large cities are most concerned about overtourism, which is unsurprising given urban spaces

\footnotetext{
${ }^{3}$ A text analysis of the twitter \#overtourism from 2014 to 2018 shows that most of the cities mentioned in connection with overtourism are Barcelona, Venice, Rome, London and Amsterdam (own analysis based on 2000 entries on twitter using the hashtag \#overtourism).
} 
have been the centres of recent anti-tourism movements. Nonetheless, residents living in close proximity to cultural sites are less concerned about overtourism threatening cultural heritage. This does not necessarily mean that residents living near cultural sites are less concerned about overtourism in general, but a potential explanation for our findings could be that the adverse effects of overtourism is felt more strongly by those who live close to heritage sites. This proximity more directly impacts on residents' quality of life and daily activities, and local residents may view the site as a cause of overtourism as opposed to something that needs to be protected from it. Thus, heritage-driven overtourism may still be perceived negatively by the local community, which is similar to the findings in Rasoolimanesh et al. (2019). However, in order to verify this, a new survey is needed to gain further insights for Europe. In contrast, for those who live further from heritage sites, overtourism is more of an abstract concept that does not personally impact on the residents' quotidian existence and thus is deemed a greater threat to cultural heritage, particularly due to the heavy stress placed on sites which, even with careful control, often leads to significant site degradation. These initial findings illustrate the complexity of overtourism in European urban areas by focusing on heritage sites and local populations, which paves the way for future research in this area and fills a clear gap in the literature.

\section{REFERENCES}

Adie, B.A. (2019). World Heritage and Tourism: Marketing and Management. Abingdon, UK: Routledge. Amore, A. (2019). Tourism and Urban Regeneration: Processes Compressed in Time and Space. Abingdon, UK: Routledge.

Ashworth, G. \& Page, S. (2011). Urban tourism research: Recent progress and current paradoxes. Tourism Management, 32(1), 1-15.

Cheer, J.M., Milano, C., \& Novelli, M. (2019). Tourism and community resilience in the Anthropocene: Accentuating temporal overtourism. Journal of Sustainable Tourism, 27(4), 554-572.

Cheung, K.S. \& Li, L.-H. (2019). Understanding visitor-resident relations in overtourism: Developing resilience for sustainable tourism. Journal of Sustainable Tourism, 27(8), 1197-1216. 
Litvin, S.W., Smith, W.W., \& McEwan, W.R. (2019). Not in my backyard: Personal politics and resident attitudes toward tourism. Journal of Travel Research. https://doi.org/10.1177/0047287519853039.

Muler Gonzalez, V., Coromina, L., \& Galí, N. (2018). Overtourism: residents' perceptions of tourism impact as an indicator of resident social carrying capacity-case study of a Spanish heritage town. Tourism Review, 73(3), 277-296.

Neuts, B., \& Nijkamp, P. (2012). Tourist crowding perception and acceptability in cities: An applied modelling study on Bruges. Annals of Tourism Research, 39(4), 2133-2153.

Novy, J. \& Colomb, C. (2019). Urban tourism as a source of contention and social mobilisations: A critical review. Tourism Planning \& Development, 16(4), 358-375.

Phi, G.T. (2019). Framing overtourism: A critical news media analysis. Current Issues in Tourism. https://doiorg.proxy.unimib.it/10.1080/13683500.2019.1618249.

Popp, M. (2012). Positive and negative urban tourist crowding: Florence, Italy. Tourism Geographies, 14(1), $50-72$.

Rasoolimanesh, S.M., Roldán, J.L., Jaafar, M., \& Ramayah, T. (2017). Factors influencing residents' perceptions toward tourism development: Differences across rural and urban World Heritage Sites. Journal of Travel Research. 56(6), 760-775.

Rasoolimanesh, S.M., Taheri, B., Gannon, M., Vafaei-Zadeh, A. \& Hanifah, H. (2019). Does living in the vicinity of heritage tourism sites influence residents' perceptions and attitudes?. Journal of Sustainable Tourism. https://doi.org/10.1080/09669582.2019.1618863.

Seraphin, H., Sheeran, P., \& Pilato, M. (2018). Over-tourism and the fall of Venice as a destination. Journal of Destination Marketing \& Management, 9, 374-376.

Vong, L.T.-N. (2015). The mediating role of place identity in the relationship between residents' perceptions of heritage tourism and place attachment: The Macau youth experience. Journal of Heritage Tourism, 10(4), 344-356. 
Table 1. Ordered probit estimations of tourism threat perception of cultural sites in Europe Probability that respondents totally agree

(i)

country AT (Reference category DE-West)
BE
BG
CY
CZ
DE-EAST

DK

EE

ES

$\mathrm{FI}$

FR

GB

GR

$\mathrm{HR}$

$\mathrm{HU}$

IE

IT

LT

LU

LV

MT

$\mathrm{NL}$

PL

PT

RO

SE

SI

SK

Small city (rural)

Large city

Living nearby historical monuments or sites

Living nearby works of art

Living nearby festivals

Middle class (ref lower)

Upper middle class

Upper class

Control variables: age class, gender,children, occupation, labour market status

\# obs.

Notes: Asterisks ${ }^{* * *},{ }^{* *},{ }^{*}$ denote significance at the $1 \%, 5 \%$ and $10 \%$ level, respectively. This table reports the marginal effects, dy/dx, and the corresponding $z$ values. Thresholds included but not reported. (ii)

\begin{tabular}{|c|c|c|c|c|c|}
\hline coeff. & & z-stat & $\mathrm{dy} / \mathrm{dx}$ & & z-stat \\
\hline 0.396 & $* * *$ & 8.19 & 0.076 & *** & 8.17 \\
\hline 0.531 & $* * *$ & 11.26 & 0.102 & $* * *$ & 11.21 \\
\hline 0.183 & $* * *$ & 3.47 & 0.035 & *** & 3.46 \\
\hline 0.058 & & 0.87 & 0.011 & & 0.87 \\
\hline 0.466 & $* * *$ & 10.28 & 0.090 & *** & 10.26 \\
\hline 0.018 & & 0.31 & 0.003 & & 0.31 \\
\hline 0.030 & & 0.58 & 0.006 & & 0.58 \\
\hline 0.377 & $* * *$ & 7.65 & 0.072 & *** & 7.64 \\
\hline 0.337 & $* * *$ & 6.42 & 0.065 & *** & 6.39 \\
\hline 0.768 & $* * *$ & 15.78 & 0.147 & ${ }^{* * *}$ & 15.62 \\
\hline 0.116 & ${ }^{* *}$ & 2.31 & 0.022 & $* *$ & 2.31 \\
\hline 0.279 & $* * *$ & 5.98 & 0.054 & $* * *$ & 5.96 \\
\hline 0.020 & & 0.40 & 0.004 & & 0.40 \\
\hline 0.681 & ${ }^{* * *}$ & 13.39 & 0.131 & ${ }^{* * *}$ & 13.25 \\
\hline 0.304 & $* * *$ & 5.99 & 0.058 & $* * *$ & 5.97 \\
\hline 0.636 & ${ }^{* * *}$ & 12.26 & 0.122 & $* * *$ & 12.12 \\
\hline 0.457 & $* * *$ & 8.91 & 0.088 & $* * *$ & 8.86 \\
\hline 0.277 & $* * *$ & 5.70 & 0.053 & $* * *$ & 5.70 \\
\hline 0.493 & ${ }^{* * *}$ & 8.28 & 0.095 & ${ }^{* * *}$ & 8.25 \\
\hline 0.176 & $* * *$ & 3.59 & 0.034 & $* * *$ & 3.59 \\
\hline 0.383 & $* * *$ & 6.30 & 0.074 & ${ }^{* * *}$ & 6.28 \\
\hline 0.263 & $* * *$ & 5.37 & 0.050 & $* * *$ & 5.36 \\
\hline 0.790 & $* * *$ & 16.26 & 0.152 & $* * *$ & 16.11 \\
\hline 0.470 & ${ }^{* * *}$ & 9.75 & 0.090 & ${ }^{* * *}$ & 9.72 \\
\hline 0.487 & $* * *$ & 9.23 & 0.094 & $* * *$ & 9.17 \\
\hline 0.013 & & 0.25 & 0.003 & & 0.25 \\
\hline 0.290 & $* * *$ & 5.85 & 0.056 & $* * *$ & 5.84 \\
\hline 0.803 & $* * *$ & 17.05 & 0.154 & $* * *$ & 16.86 \\
\hline 0.017 & & 1.00 & 0.003 & & 1.00 \\
\hline 0.067 & ${ }^{* * *}$ & 3.81 & 0.013 & $* * *$ & 3.80 \\
\hline-0.034 & ** & -2.27 & -0.006 & ${ }^{* *}$ & -2.27 \\
\hline 0.010 & & 0.59 & 0.002 & & 0.59 \\
\hline-0.087 & $* * *$ & -5.77 & -0.017 & $* * *$ & -5.76 \\
\hline 0.061 & $* * *$ & 4.06 & 0.012 & $* * *$ & 4.05 \\
\hline 0.065 & ** & 2.15 & 0.012 & ** & 2.15 \\
\hline 0.040 & & 0.50 & 0.008 & & 0.50 \\
\hline
\end{tabular}

26028 